\title{
Technologies in organic farming: consumers' values and acceptance
}

\section{Lassen, $J$.}

Department of Food and Resource Economics, University of Copenhagen, Rolighedsvej 25, 1958 Frederiksberg C, Denmark.jlas@ifro.ku.dk

\begin{abstract}
In organic farming a dilemma is posed by the heavy reliance on nutrients from conventional livestock farming. For Danish organic plant producers the influx of conventional nutrients accounts for up to $70 \%$ of their nutrients. Facing this problem, Danish organic farmers' organizations have decided to phase out their use of conventional manure before 2021. This, however, raise a number of questions about consumers' acceptance of the alternative technologies that have been proposed to close the nutrient gab. Drawing on qualitative interviews with Danish organic consumers, this paper first discusses what, from a consumers perspective, characterizes the technologies consumers associate with organic production. This part of the analysis shows that by and large consumers regard organic technologies as the opposite of conventional farming. Second, consumers' perceptions of solutions suggested to close the nutrient gap by recycling sewage sludge, and in particular the criteria applied when these technologies are assessed, are analysed. This part of the analysis shows how organic consumers base their assessment of alternative strategies and technologies primarily on concerns about environmental risks (pollution) and consequences for human health. Broader ideas about ecosystems and the recycling of nutrients between the agricultural sector and the urban population are notably absent. On the basis of these findings the paper concludes by discussing the relationship between the consumers' values that guide what is perceived as an acceptable organic technology and the ideological principles behind organic production systems as they are formulated by the International Federation of Organic Agriculture Movements (IFOAM).
\end{abstract}

Keywords: Agriculture, perceptions, sewage sludge, nutrient gap

\section{Introduction}

In 2008, following years of internal discussions, the two Danish societies for organic farmers, Økologisk Landsforening (ØL) and Sektion for Økologi (SØ), made a decision in principle to phase out use of conventional manure in organic plant production and straw in organic animal production by 2021. On the one hand, this would resolve a problem faced not only by organic producers in Denmark, but also in countries around the world (Oelofse, Jensen, \& Magid, 2013): namely, the fact that organic production, in its present form, is closely intertwined with the conventional agricultural sector it sees itself as an alternative to. Thus organic agriculture as a whole cannot be seen as living up to the ideal of recycling, one of the core elements in the principles of ecology laid out by the International Federation of Organic Agriculture Movements (IFOAM) (IFOAM, n.d.).

The seriousness of the challenge is illustrated by the fact that conventional manure, mostly from the largely criticized and intensive pig production, accounted for about $70 \%$ of the total input of nutrients in Danish organic plant production in 2010. The discussions in L $\varnothing$ and $S \varnothing$ leading up to the 2008 decision were heated, not least because phasing out conventional nutrients would be a much smaller challenge to organic dairy producers - who by and large have plenty of nutrients - 
than to plant producers. In addition, suitable alternative nutrient sources and technologies were not easy to identify.

Some of the technologies put forward to fill the nutrient gap following the 2008 decision represent a radical vision of recycling. They involve returning nutrients which leave the agricultural sector in the shape of food products to be consumed in the cities to organic plant production in the shape of sewage sludge. It is, however, unclear how such a change in organic agriculture would be received by consumers of organic food. By scrutinizing the arguments and explanations organic consumers give when they are asked whether or not a technology is relevant to organic production, this paper aims to reveal the underlying values organic technologies must meet to be acceptable from a consumer's point of view.

\section{Method}

The paper draws on the empirical results of five focus groups of 7-8 persons (total $n=39$ ) conducted in September 2012. Across the groups, participants were recruited paying respect to educational background age and gender. In addition, only organic consumers were recruited. These were defined as consumers who had either purchased an organic product in the two weeks preceding the recruitment interview or agreed that organic farming should be promoted.

The interviews were carried out in Copenhagen (two groups); Kolding, a provincial town (two groups) and Christiansfeld, representing a rural area (one group). All participants were recruited through an analysis company in a topic-blinded manner. Each focus group discussion lasted approximately 2 hours and organised around four themes as follows. 1: Organic foods in an everyday perspective. 2: Organic production in a societal perspective. 3: Organic technologies. 4: Actors responsible for solving the nutrient problem. This paper is based primarily on an analysis of themes 2 and 3, where the participants were encouraged to discuss organic technologies.

In theme 2 participants were asked to write down any keywords they associated with organic agriculture. They were reminded that the organic products they had been discussing in the previous theme originated from a production system. This was followed, in theme 3 , by a section where participants were asked to reflect on the technologies they associate with organic plant production. Drawing on previous research on the importance of contexts for expressed themes and values (Korzen \& Lassen, 2010), the intention of these sections was to encourage the participants to discuss technologies rather than products, and thus illuminate what in general, and specifically for plant production, characterises an organic technology.

The second part of theme 3 involved a more structured approach, where participants were first introduced to, and subsequently discussed, the problem of the nutrient gap, and the decision to close it. Following this, participants were shown six cards suggesting different technological solutions to the problem. These included three sewage sludge-related solutions that will be analysed in this paper: use untreated sewage sludge; use composted sewage sludge, and use phosphate extracted from sewage sludge. The intention of this section was to illuminate the interviewees' perceptions of the different solutions to the problem of phasing out conventional nutrients, and in this way to facilitate an analysis of the values drawn on in such assessments. 
The focus group interviews were recorded and transcribed verbatim. Stephen Toulmin's approach to the analysis of argumentation (Toulmin, 2003) was applied in order to identify and analyse the core arguments that participants were deploying when they responded to questions about organic technologies.

\section{What is an organic technology?}

It is striking that in the general discussions of organic technologies interviewees most often characterise organic agriculture by saying what it is not. Accordingly, organically relevant technologies are often identified by references to their counterparts in conventional production systems: organic production methods are those not using pesticides, not using artificial fertilizers or not relying on genetic manipulation, and so on. Occasionally there is an explicit reference to conventional agriculture, but most often the comparison is tacit or implicit - as in the following exchange, where Carsten define organic agriculture: The first that comes into my mind, when I think of the organic, that is of course the farmer doesn't spray-and I suppose this is also true for market gardening. And they neither use straw shortener or other crop sprays; and this must be positive for nature - for plants and animals in nature. This was actually what came into my mind

This is one of the relatively few examples where organic technologies are justified with reference to nature and the environment - in this case pesticides and the use of straw-shortening chemicals are presented as positive organic technologies because of the benefits for plants and animals. By contrast, the avoidance of pesticides and other auxiliary chemicals is more often discussed within a frame of health: organic technologies here are favoured because the products are not as contaminated with chemicals or because the working environment is free from chemicals. Alberte, for example, argues in favour of organic vegetable production in greenhouses, justifying it with reference to consumer as well as worker health: ...the first [thing] I wrote was better working environment, as Anne says, because of the working conditions and all the poisons, sprayed in the greenhouses. It is not fair that people are exposed to this-and I'm sure that less [poison] will end up in our body if we eat things other than these sprayed vegetables.

Quite often links between organic technologies and, say, pesticide-free agriculture are followed by positive accounts of alternative pest control. These are both referred to in general with terms like biological pest control or (less often) by specifying the alternatives - as happens here, when David talks about alternatives like predatory mites, revealing a high degree of insight into (organic) agricultural technologies: And that makes me think about - and that's definitely something they use in greenhouses - these biological pest controls, that is predatory mites. And then I think about this awful quantity of fruit... with deceases, because it will be affected.

The auxiliary chemicals closely connected with conventional production, but not with organic production systems, are often discussed within a critical frame of efficiency and unnaturalness. At the core here is the notion that virtues of conventional agriculture are speed and efficiency, and the idea that this is achieved by artificial - that is, not natural - means such as chemical sprays, genetic manipulation, and so on. By contrast, organic agriculture, because of its limited use of chemicals and high-tech solutions, is seen as more natural. Core features of organic production here seem to be that plants and fruit should not be harvested until they are ripe, that growth (or breeding) should not be accelerated, but follow the pace of nature. Time, or rather 
slowness, is seen as an important aspect of organic agriculture. So, organic technologies are perceived as technologies which embody naturalness and induce slowness. This is expressed by Ejvind when he explains why he dislikes the way conventional agriculture fiddles with things. His argument in favour of organic production is supported via a link between the slowness of organic agriculture and a more natural and therefore desirable production system: Really, [in organic farming] it is something natural, coming out of the soil, without anybody fiddling too much. ...like a real seed, you could say, coming out of the soil, when you water it. It's not something that has been grafted, where they have used straw shorteners or whatever they do to make them grow faster... I suppose that that's what it is about [in conventional agriculture], and that is not a very nice idea...

Following the pace of nature in organic production is often seen as a good thing in itself, a positive aspect that needs no elaboration or backing - "a nice idea", as Ejvind express it. It is, however, striking that on the few occasions on which participants say why naturalness is desirable, the explanations they offer are only once linked to the idea that following the speed of nature ensures that plants are more robust in coping with pests. Typically, the explanations have instead to do with a perceived and positive association between naturalness and better health, improved taste, or being more filling, although some interviewees were also concerned about reduced shelf-life.

\section{Closing the gap: Recycling nutrients}

Considering that that one of the pillars, or ideals, of organic plant production is the recycling of nutrients and abandonment of artificial fertilizers, these very issues were taken up by surprisingly few participants during sections of the discussion dealing with organic technologies in general. One of the groups omits to address the issue at all, and in the others, soil enrichment and closing the nutrient cycle are typically addressed in passing, and never discussed in detail. In groups where nutrients were discussed within the framework of nutrient recycling, it is striking the participants never take up nutrient recycling beyond the farm gate. That is, they only address farm-level circuits such as using manure, harvested weed and crop rotation as a means of providing nutrients.

However, some like Bjarne, below, express uncertainty about whether these strategies are actually applied in organic plant production. Bjarne sees organic agriculture as a practice moving towards what he understands as sustainable agriculture, or in other words an agricultural practice not exhausting the fertility of the soil. It would be clever, in the long view, if organic agriculture would be what you consider as truly sustainable, so we don't exhaust [the soil].

Hardly any of the participants were aware of the reliance of organic production on conventional manure. Although some received this information with a shrug, most reacted with disappointment or disillusion. Thus Birgit said: This makes me think, well, maybe it doesn't really make a difference buying organic products, if the difference is so small. Although I would still by some products organic. Some clearly see organic farming as the good and sustainable alternative - as a sort of golden standard meeting the highest requirements. From this perspective, organic farming's reliance on conventional farming is shocking and makes it hard to see the point of organic farming. 
While some participants are more positive than others, discussions of the three alternative sludge technologies show that none of the focus groups embraced these solutions. The solution least accepted was the use of untreated sludge, followed by composted sludge. Extracted phosphorous was seen as most acceptable. Despite this, and although there was frequent criticism of the present reliance on conventional nutrients, several of the groups ended up agreeing that none of the sludge-based technologies are better alternatives.

In discussions of the pros and cons of the technologies most arguments are related to the risks, to nutrients as a scarce resource, and to discomfort at the idea of mixing human lavatory waste with food. It is thus remarkable that during these discussions, following the presentation of the dilemma, the issue of recycling is only taken up once in one group. This happened when Alice, towards the end of the discussion of sludge-based technologies, said: I believe [the soil] has been exhausted since the fifties. We need to supply some nutrients. After all we are removing products and we take away energy: we need to return it. It is too easy; it doesn't work properly. It's like the heathland in the 50'ies. Considering that the sewage-based solutions are clearly technologies that close the cycle, it is surprising that this topic is not taken up in any of the other groups.

The only arguments presented invoking the flow of nutrients revolved around scarce resources. To some participants the utilisation of an unexploited resource is an advantage of the sewage technologies. Thus Anja says: ... there must be a surplus [of sludge] somewhere; what happens to that? If they just dump it in the sea, it doesn't make a difference. You might as well make use of it [in organic farming]. As in the discussions above, organic farming is not seen as part of a larger system where energy and matter ideally circulate. It is regarded as an enterprise, like conventional farming, with inputs and outputs - the basic difference lying in the quality of the inputs, and hence also the outputs.

Most arguments about the sludge-based technologies relate to their risks. While some participants felt confident that once the use of sewage sludge is approved for organic farming, we must assume that the authorities have examined the risks, several expressed concerns about risks. When these risks were appealed to in order to argue for or against the technologies, health risks seem to predominate. But it was often not clear whether the interviewees were talking about health or environmental risks - as can be seen in this discussion between three participants: Allan: I get some horror visions: what is in [the sludge]? Astrid: 'Sludge'-just thinking about it! Alice: It's full of hormones. Allan: Yes, hormones and heavy metals! Alice: Contraceptive pills... Anne: It's disgusting. Environmental risks were particularly important in assessments of phosphorus extraction, because that process requires high temperatures and thus large quantities of fossil fuels.

Many of the negative reactions to the sludge-based technologies relate to the fact that they mix categories. In line with the views of Mary Douglas (Douglas, 1966), the technologies are often seen as more risky and thus more unacceptable because they mix sludge from, and therefore associated with, the lavatory with organic production associated with food. This is indirectly expressed in Anne's last remark in the quote above; but is sometimes also expressed more clearly, as happens in the following discussion: Else: Is cowpat any better that human shit? Emma: Yes, definitely! There are all the medical residues. Esben: There are also medicinal residues in cowpat, just so you know it! ... Emma: I find human faeces more repulsive than cow[pat]. 
Finally it should be noted that economic concerns surfaced in the arguments about the technologies. These related to rising consumer prices, as well as concerns about the economic performance of the Danish organic sector.

\section{Discussion}

The analysis above points to a number core values which consumers connect with organic technologies.

First, it should be noted that consumers base their assessments on a number of values which are also visible in the principles for organic farming stated by IFOAM (IFOAM, n.d.). These shared values include risks to health, to the environment and to workers (the latter all included in IFOAM's principle of health). Although it is not always stated directly, consumer concern about risks is closely related to a demand for caution. The feeling is that knowledge in the area is limited, and that accordingly we should exercise caution - another key value principle stated by IFOAM in their principle of care.

Second, the organic consumers do at some points diverge from IFOAM's principles. It is less surprising that the principle of fairness, stating that organic agriculture should build in fairness, in the common environment and life opportunities, is not a value people use to decide whether a technology is acceptable or nor. After all, fairness is not a major issue in debates over Danish organic production. It is, however, striking that recycling, a key element in the principle of care, is more or less absent as well: at this point consumers diverge from one of the pillars of organic agriculture.

Third, organic consumers seem to base their assessments of organic technologies on a hybrid value best described as 'naturalness/slowness'. This value and its components are not expressed directly in the organic principles.

Fourth, and finally, these differences between official organic principles and consumer belief should be heeded: they show that decision makers in the organic food system need to consider the new technologies they want to introduce into organic agriculture in the future with care.

\section{References}

Douglas, M. (1966). Purity and danger. An analysis of the concepts of pollution and taboo. London: Routledge.

The International Federation of Organic Agriculture Movements (IFOAM). (n.d.). Principles of organic agriculture.

Korzen, S., \& Lassen, J. (2010). Meat in context. On the relation between perceptions and contexts. Appetite, 54(2): 274-281.

Oelofse, M., Jensen, L. S., \& Magid, J. (2013). The implications of phasing out conventional nutrient supply in organic agriculture: Denmark as a case. Organic Agriculture, 3(1): 41-55.

Toulmin, S. (2003). The uses of argument. Cambridge University Press. 